\title{
Insuficiencia hepática aguda fulminante por virus de la hepatitis B: reporte de caso
}

\section{Acute liver failure due to hepatitis B: a case report}

\author{
Ana Madeleine Barrera L, Laura Daniela Rincón, ${ }^{2}$ Fernando Peñaloza Cruz, MD, ${ }^{3}$ Lina Patricia Vargas N, ${ }^{4}$ Farhi Alonso Delgado Medina. ${ }^{5}$
}

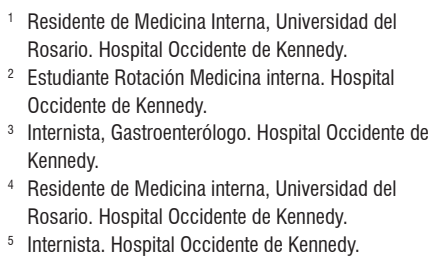

2 Estudiante Rotación Medicina interna. Hospital

Occidente de Kennedy.

3 Internista, Gastroenterólogo. Hospital Occidente de Kennedy.

${ }^{4}$ Residente de Medicina interna, Universidad del

Rosario. Hospital Occidente de Kennedy.

5 Internista. Hospital Occidente de Kennedy.

Fecha recibido: $22-11-13$

Fecha aceptado: 21-07-15

\begin{abstract}
Resumen
Se reporta el caso de una mujer de 37 años de edad sin antecedentes relevantes, que consulta por cuadro febril ictérico asociado con alteración hepática importante con patrón necroinflamatorio, se documenta hepatitis viral $\mathrm{B}$ y presenta una evolución tórpida rápida hasta la muerte. De esta forma, se exponen los posibles factores que influyen en la progresión hacia la insuficiencia hepática fulminante (IHF) descritos en la literatura.

Palabras clave

Insuficiencia hepática aguda, hepatitis B, causalidad, mutación y virus y B, terapéutica.

\section{Abstract}

We report the case of a 37 year old woman who came to the hospital because of jaundice and a fever. Her symptoms were associated with significant liver impairment and a necroinflammatory pattern due to viral hepatitis $B$ although she had no relevant medical history. Her symptoms developed rapidly until death. We present the factors that may have influenced her progression to fulminant liver failure as described in the literature.
\end{abstract}

Keywords

Acute liver failure, causes of hepatitis B, hepatitis B virus, hepatitis B viral mutations, hepatitis B therapy.

\section{INTRODUCCIÓN}

La insuficiencia hepática fulminante (IHF) es una severa lesión aguda, de presentación infrecuente, relacionada con una necrosis hepática aguda inducida, probablemente por una respuesta inmune exagerada en el caso de la hepatitis viral o, como se describe en la mayoría de las series, por intoxicación de acetaminofén. Se describe típicamente como encefalopatía y tiempos prolongados (INR $>1,5$ ), que dependiendo del tiempo de evolución entre los síntomas y el desarrollo de encefalopatía, se clasifica en hiperaguda, aguda y subaguda.

Por ser una entidad rara, no se cuenta con estudios a gran escala que describan su historia natural o nivel de evidencia para su manejo; sin embargo, la American Association for the
Study of Liver Diseases (AASLD), en el 2011, presentó una revisión a fondo como opinión de expertos del documento publicado en el 2005 con respecto al diagnóstico, tratamiento y expectativas del trasplante.

El presente artículo busca poner en contexto las limitaciones en el oportuno diagnóstico de la etiología de la insuficiencia hepática, así como el adecuado manejo de la misma. Además, se realiza una breve revisión de tema con énfasis en los factores que influyen en la evolución de la infección por hepatitis B hacia la insuficiencia hepática fulminante.

\section{DESCRIPCIÓN DEL CASO}

Paciente femenina de 37 años sin antecedentes relevantes, natural de la ciudad de Ibagué, Tolima, procedente de la 
ciudad de Bogotá DC, que consulta por 4 días de dolor abdominal difuso asociado con fiebre subjetiva y tinte ictérico; al examen físico: tensión arterial (TA) 120/70, frecuencia cardíaca (FC) $80 x \mathrm{~min}$, frecuencia respiratoria (FR) $18 x$ min, saturación $\mathrm{O}_{2} 93 \%$, fracción inspirada $\mathrm{O}_{2}$ 0,21 , ictérica, sin dificultad para respirar, sin ingurgitación yugular, cardiopulmonar normal, abdomen doloroso a la palpación en epigastrio e hipocondrio derecho pero sin irritación peritoneal, sin signos de hepatopatía crónica y neurológicamente sin focalización ni criterios de encefalopatía. Los paraclínicos de ingreso mostraban su perfil hepático alterado con un patrón predominantemente necroinflamatorio, con bilirrubinas (bilirrubina total de $7,58 \mathrm{mg} /$ $\mathrm{dL}$ y directa de $5,97 \mathrm{mg} / \mathrm{dL}$ ), transaminasa glutámico pirúvica (TGP) de $6,315 \mathrm{mg} / \mathrm{dL}$ y transaminasa glutámico oxaloacética (TGO) de 8,947 mg/dL, PT de 24 e INR de 1,8; dentro de otros estudios, glucemia $114 \mathrm{mg} / \mathrm{dL}$, electrolitos con hiponatremia probablemente en relación con deshidratación $(\mathrm{Cl}, 99,4 ; \mathrm{Na}, 130 ; \mathrm{K}, 3,65)$, sin compromiso de la función renal (creatinina 0,56, nitrógeno ureico en sangre [BUN] 14,7) y ecografía hepática reportada con cambios sugestivos de hepatitis.

Se ingresa por alto riesgo de insuficiencia hepática para observación clínica y estudio de hepatopatía, se inicia reanimación hídrica y estudios de hepatopatía, con perfil viral (antígeno de superficie de la hepatitis B [AgsHB]HVC-HVA total-IgM Hep E-IgG-M, varicela zóster), perfil inmunológico (ANAS-ASMA), y niveles de ceruloplasmina y cobre. Se interrogó a la paciente y su familia sin referir historia de alcoholismo, por lo que no se consideró probable este origen, así como tampoco tóxica, dado que no referían ingesta de medicamentos homeopáticos o evidencia de ingesta de dosis exagerada de acetaminofén.

Durante los primeros 3 días de estancia hospitalaria permaneció hemodinámicamente estable, sin signos de encefalopatía hepática pero con empeoramiento de perfil hepático y deterioro de función hepática; se recibe reporte del AgsHB siendo francamente positivo, por lo cual se solicita AgeHBanti-AgeHB y anti-Core total HB, Ac Hep D (los cuales eran de remisión) para evaluar si se trataba de una infección aguda y/o crónica reactivada y se inicia entecavir $0,5 \mathrm{mg} /$ día y la remisión para trasplante hepático. Dentro de otros estudios, referenciados en la tabla 1 , se encontraba la LDH elevada, de la cual se ha descrito su elevación en el período prodrómico y es máxima al inicio de la ictericia en las hepatitis virales, y en este caso, dado su valor, se consideró como marcador de necrosis celular hepática en relación con la progresión de la función hepática, como se observa en la figura 1 .

$\mathrm{Al}$ cuarto día presenta deterioro del estado general, con encefalopatía hepática grado II, se inicia manejo con lac-

Tabla 1. Evolución paraclínica.

\begin{tabular}{|c|c|c|c|c|c|}
\hline & 11-sep-13 & 12-sep-13 & 14-sep-13 & 15-sep-13 & 16-sep-13 \\
\hline AST & 8947 U/L & $12048 \mathrm{U} / \mathrm{L}$ & $10428 \mathrm{U} / \mathrm{L}$ & $5557 \mathrm{U} / \mathrm{L}$ & $3450 \mathrm{U} / \mathrm{L}$ \\
\hline ALT & $6315 \mathrm{U} / \mathrm{L}$ & $8041 \mathrm{U} / \mathrm{L}$ & $7010 \mathrm{U} / \mathrm{L}$ & $6202 \mathrm{U} / \mathrm{L}$ & $4416 \mathrm{U} / \mathrm{L}$ \\
\hline BT & $7,58 \mathrm{mg} / \mathrm{dL}$ & & $13,78 \mathrm{mg} / \mathrm{dL}$ & $14,2 \mathrm{mg} / \mathrm{dL}$ & $13 \mathrm{mg} / \mathrm{dL}$ \\
\hline $\mathrm{BD}$ & $5,97 \mathrm{mg} / \mathrm{dL}$ & & $9,16 \mathrm{mg} / \mathrm{dL}$ & $10,3 \mathrm{mg} / \mathrm{dL}$ & $8,5 \mathrm{mg} / \mathrm{dL}$ \\
\hline Albúmina & $4 \mathrm{~g} / \mathrm{dL}$ & & $2,9 \mathrm{~g} / \mathrm{dL}$ & & $3,2 \mathrm{~g} / \mathrm{dL}$ \\
\hline $\mathrm{CH}$ & PLT 150000 & PLT 134000 & PLT 166000 & PLT 278000 & PLT 273000 \\
\hline PT & 24 & 37 & 101 & No Coagula & No Coagula \\
\hline PTT & 35 & 40 & & 65 & 61 \\
\hline INR & 1,8 & 2,9 & 8,91 & ---- & ---- \\
\hline Creatinina & $0,56 \mathrm{mg} / \mathrm{dL}$ & & & $1,1 \mathrm{mg} / \mathrm{dL}$ & $0,8 \mathrm{mg} / \mathrm{dL}$ \\
\hline BUN & 14 mg/dL & & & & $9,7 \mathrm{mg} / \mathrm{dL}$ \\
\hline NA & $130 \mathrm{mEq} / \mathrm{L}$ & & & $145 \mathrm{mEq} / \mathrm{L}$ & $152 \mathrm{mEq} / \mathrm{L}$ \\
\hline K & $3,6 \mathrm{mEq} / \mathrm{L}$ & & & 4 mEq/L & 4 mEq/L \\
\hline AgsHB & & & 6075 & & \\
\hline FALK & & & $131 \mathrm{U} / \mathrm{L}$ & $196 \mathrm{U} / \mathrm{L}$ & \\
\hline LDH & & & $1852 \mathrm{U} / \mathrm{L}$ & & \\
\hline Glucemia & 114 mg/dL & & & $24 \mathrm{mg} / \mathrm{dL}$ & \\
\hline SNC & \multicolumn{2}{|c|}{ Sin encefalopatía } & \multicolumn{2}{|c|}{ Encefalopatía G III } & Encef G IV \\
\hline
\end{tabular}

AST: alanina aminotransferasa; ALT: aspartato aminotransferasa; BT: bilirrubina total; BD: bilirrubina directa; CH: cuadro hemático; PT: tiempo de trombina; PTT: tiempo de protrombina; INR: International Normalized Ratio; BUN: nitrógeno uréico; NA: sodio; K: potasio; AgsHB: antígeno superficie hepatitis B; F ALK: fosfatasa alkalina; LDH: lactato deshidrogenasa; SNC: sistema nervioso central; PLT: plaquetas. 

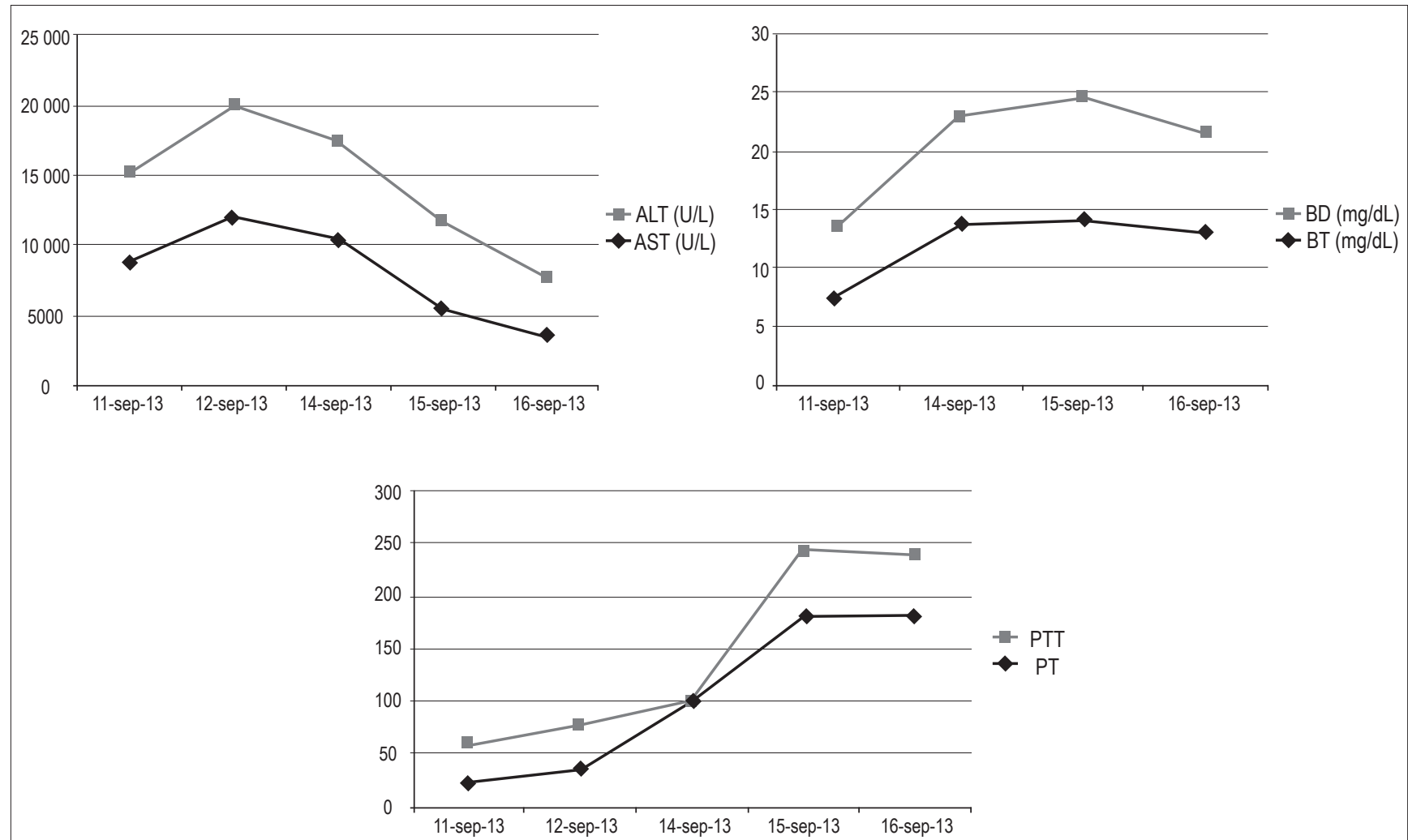

Figura 1. Evolución paraclínica de la paciente durante hospitalización.

tulosa y metronidazol como medida antiencefalopatía, y $\mathrm{N}$-acetilcisteína para manejo de la hepatopatía. Se toman gases arteriales que evidenciaban acidosis metabólica de brecha aniónica elevada relación con la insuficiencia hepática $\left(\mathrm{FIO}_{2} 0,28 ; \mathrm{pH} 7,47 ; \mathrm{PCO}_{2}, 15 ; \mathrm{PO}_{2}, 48 ; \mathrm{HCO}_{3}, 10,9\right.$; $\mathrm{SatO}_{2} 86 \%$ ) para la cual se da manejo médico con bicarbonato de sodio y se traslada a la unidad de cuidado intensivo (UCI) por progresión a encefalopatía hepática grado III y deterioro hemodinámico que requería soporte vasopresor, sin respuesta favorable. El quinto día evoluciona a encefalopatía hepática grado IV, se procede a proteger la vía aérea con intubación orotraqueal (IOT), se realiza una tomografía axial computarizada (TAC) cerebral simple (figura 2) la cual fue normal, fondo de ojo sin edema de papila, pero ante la duda de cursar con hipertensión intracraneal se da manejo con un bolo de manitol, sin mejoría clínica; luego presenta taquiarritmia tipo taquicardia supraventricular colapsante que requirió cardioversión eléctrica y farmacológica, sangrado digestivo alto para lo cual se inicia infusión de omeprazol y se transfunde plasma a $15 \mathrm{~mL} / \mathrm{kg}$ más vitamina K. La paciente progresa a paro cardiorrespiratorio que no responde a maniobras avanzadas y fallece a los 5 días de ingreso a la institución y al noveno de inicio de los sínto- mas. Se consideró como causa de muerte la insuficiencia hepática fulminante secundaria a hepatitis $\mathrm{B}$, dado que los otros estudios solicitados son de remisión por tratarse de un hospital del estado, y no se pudieron obtener resultados a tiempo, así como no fue posible su remisión a un hospital de mayor complejidad.

\section{DISCUSIÓN}

La insuficiencia hepática se define como la anormalidad de la coagulación (INR $>1,5$ ) asociada con cualquier grado de encefalopatía (tabla 2) (1) en un paciente sin cirrosis preexistente o con una enfermedad hepática de $<26$ semanas de duración (2), a la cual progresó rápidamente nuestra paciente.

Epidemiológicamente, se desconoce la incidencia de esta entidad en Colombia; sin embargo, se han reportado casos secundarios de hepatitis autoinmune en una paciente en tratamiento con interferón pegilado para infección crónica por el virus de la hepatitis C (3) y de hepatitis autoinmune (4).

En Estados Unidos y Europa, la mayoría de los casos son secundarios de causas tóxicas, la principal es la intoxicación por acetaminofén (46\%) seguida de las causas virales (12\%), 


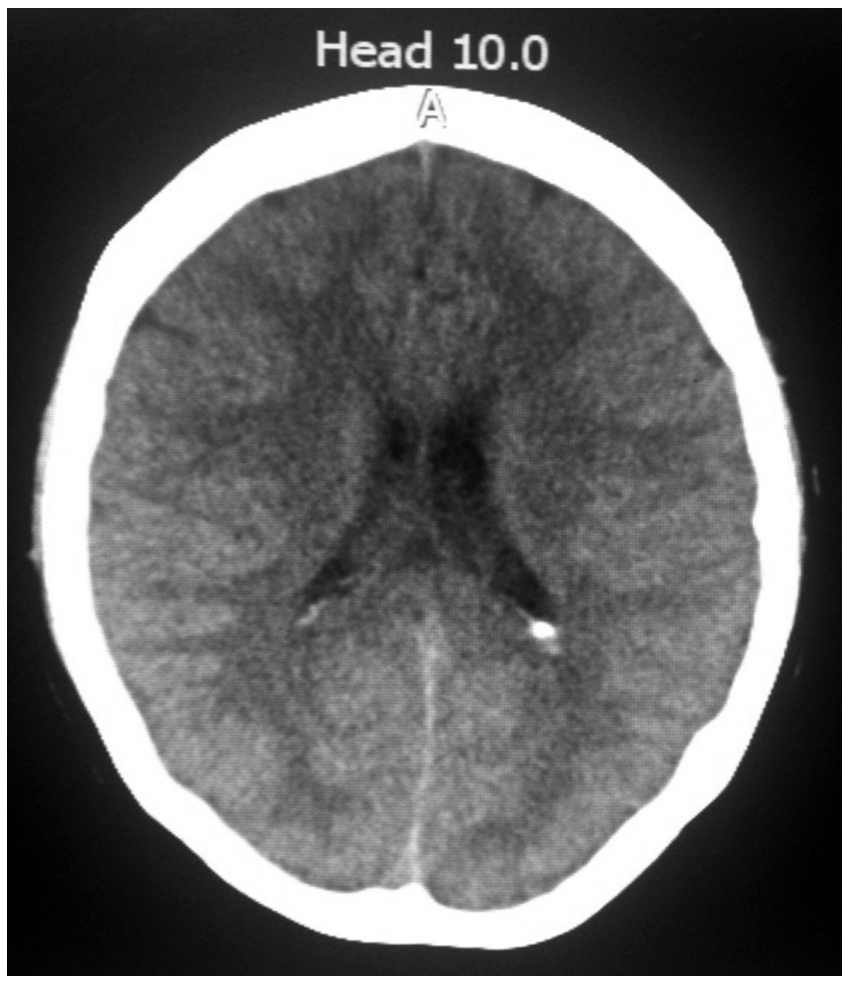

Figura 2. Tomografía axial computarizada de cráneo simple. No se evidencian hallazgos compatibles con sangrado o isquemia. No hay edema cerebral.

predominando el virus de la hepatitis B (VHB) (7\%) (5). La presentación de la IHF por hepatitis $B$ puede ocurrir desde el inicio de la infección aguda, por agudización de una infección crónica o por una coinfección por hepatitis $\mathrm{C}$ o D (6); la hepatitis E se presenta en el 15\% al 25\% de mujeres embarazadas, sobre todo en el tercer trimestre de embarazo (7-9). Otras causas descritas son las inducidas por medicamentos diferentes al acetaminofén, dentro de los que están la amiodarona, quetiapina, ácido valproico (10-13), así como también causas autoinmunes (3).

Tabla 2. Clasificación de encefalopatía hepática de West Haven.

\begin{tabular}{cl}
\hline Grado & \multicolumn{1}{c}{ Manifestación clínica } \\
\hline I & $\begin{array}{l}\text { Alteración de la concentración y alteraciones de la } \\
\text { personalidad }\end{array}$ \\
II & Somnoliento \\
III & Estupor con respuesta a estímulos dolorosos \\
IV & Coma \\
\hline
\end{tabular}

Es raro el desarrollo de una IHF por VHB, pero presenta alta mortalidad y más aún si hay coinfección con el virus de la hepatitis $\mathrm{D}$ (VHD), lo que significa un pobre pronóstico para el paciente. Un gran inóculo está relacionado con un período de incubación corto más que con la evolución a IHF, en contraste, una rápida respuesta inmune está más relacionada con el desarrollo de IHF que una replicación viral aumentada (14). Esto quiere decir que el viraje temprano de AgsHB a anti-HBS sugiere estar implicado en la patogenia de la IHF (15); además de esto, la asociación entre una mutación del VHB con el desarrollo de la insuficiencia hepática fulminante ha sido previamente reportada $(16,17)$ y se describe una mutación en el precore, core y proteínas del VHB que aparentemente induce a apoptosis del hepatocito; sin embargo, no se ha documentado que sea prerrequisito para el desarrollo de $\operatorname{IHF}(18,19)$.

Aún es incierta la fisiopatología de cómo esta mutación produce lesión hepatocelular masiva y de cómo se añade la alta respuesta inmunológica por los linfocitos $\mathrm{T}$; como una evidencia post mortem, en el examen del hígado se ve una alta necrosis masiva. Se cree que esta mutación en el precore hace una activación masiva de los linfocitos $\mathrm{T}$ o que esta mutación hace daño masivo al hepatocito por un incremento rápido de $\mathrm{HBcAg}(15)$.

Otra teoría es la alteración del óxido nítrico endotelial $(\mathrm{ONe})$ : normalmente su función es la vasodilatación para un control hemodinámico adecuado pero cuando sus niveles se encuentran disminuidos y hay un aumento en el óxido nítrico sintasa (ONs), no solo se evidencia una alteración vasoactiva, sino que se ve un incremento considerablemente tóxico por la producción de radicales libres, que terminan lesionando el endotelio; adicionalmente actúa como una sustancia proapoptótica por la activación masiva de caspasas (20). En la IHF, las células de Kupffer y los sinusoides hepáticos muestran una alta producción de ONs, lo que permite un aumento de la permeabilidad vascular y por ende, un incremento de las concentraciones de macrófagos en el hígado, además se presenta una menor cantidad de $\mathrm{ONe}$ en ductos biliares, células endoteliales y linfocitos. Adicionalmente, durante el inicio de la IHF se aprecian niveles séricos de proteína $C$ reactiva (PCR) normales, pero en estadios previos al final de la IHF se observan niveles séricos de PCR elevados (21) hasta $10 \mathrm{mg} / \mathrm{dL}$. Antes de que el hígado pierda su capacidad de síntesis proteica y la PCR empiece a disminuir, los niveles de factores de coagulación también se encontrarán disminuidos, tales como el factor $\mathrm{V}$, proteína $\mathrm{S}$ y proteína $\mathrm{C}$ asociados con niveles séricos de bilirrubinas elevadas. No se midieron estos factores de coagulación, sin embargo los tiempos de coagulación incalculables sumados a las bilirrubinas en ascenso y transaminasas inicialmente elevadas, y luego su descenso paralelo con el incremento de los tiempos de coagulación y bilirrubinas, evidenciaban de manera fisiológica la progresión de la insuficiencia hepática. Asimismo, los niveles de PCR pueden ser un predictor de la progresión de la IHF y su severidad (22), de aquí parte la afirmación 
respecto al tratamiento con prostaciclina; sin embargo, esto no ha demostrado beneficio y sí mayor riesgo de complicaciones (23). En nuestra institución, no se contaba en el momento con medición de PCR, por lo cual no se tiene este dato para el presente caso.

De acuerdo con el tiempo entre el inicio de la ictericia y el desarrollo de la encefalopatía, se han descrito diferentes clasificaciones que proporcionan pistas sobre la causa de la enfermedad, posibles complicaciones, y el pronóstico con tratamiento de acuerdo con el intervalo (figura 3) (24). En nuestra paciente, sin contar con las limitaciones para el adecuado diagnóstico y manejo, su cuadro evolucionó en 7 días, por lo tanto es un caso de insuficiencia hepática aguda o fulminante.

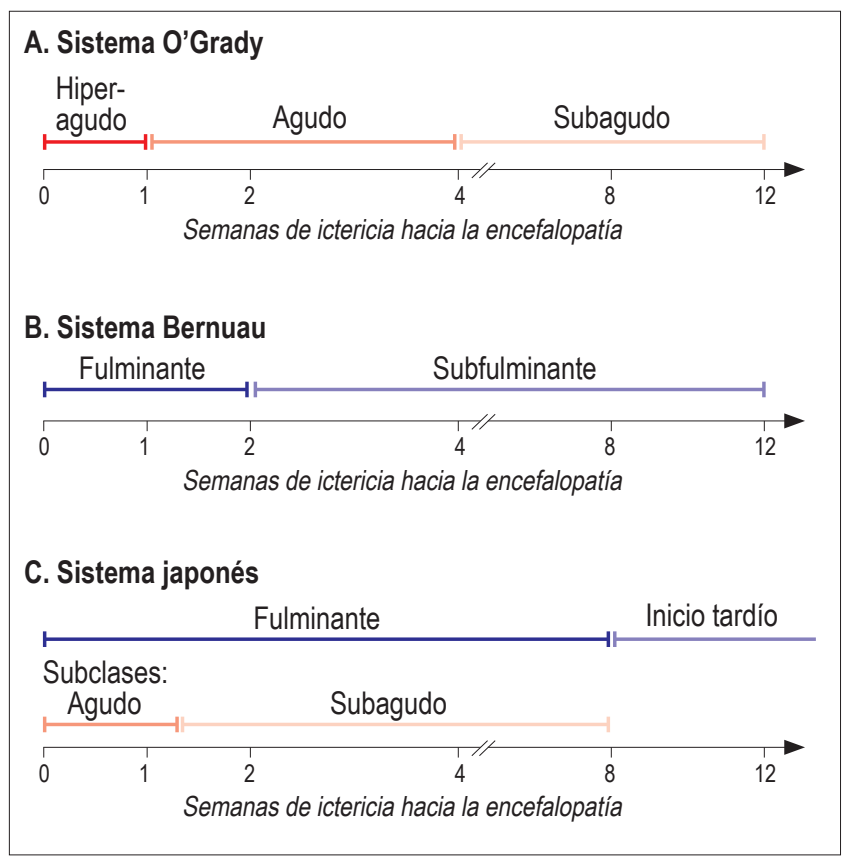

Figura 3. Sistemas de clasificación de la insuficiencia hepática aguda (modificada de: Bernal W, N Engl J Med. 2013;369:2525-34).

Todos estos pacientes deben manejarse en la UCI con el fin de estabilizar y controlar las complicaciones que se derivan de la IHF y como puente al trasplante hepático, dado que es el único tratamiento efectivo en la mayoría de las situaciones (25). Mientras esto ocurre, se sugiere iniciar el estudio etiológico con base en la tabla 3 y realizar un manejo con enfoque en problemas, teniendo en cuenta factores predictores de mal pronóstico como guía para selección de prioridad de trasplante (6).

\section{Encefalopatía}

El edema cerebral es la mayor causa de mortalidad en los pacientes con IHF y ocurre principalmente en la presenta- ción hiperaguda. Prevenir y manejar la hipertensión intracraneal (HIC) es el primer eslabón en el manejo de estos pacientes: para pacientes con encefalopatía hepática grado I y II es recomendable minimizar los estímulos, posicionar la cabecera a $30^{\circ}$; y la IOT para grados III y IV, como se realizó en nuestra paciente. Se habla de HIC severa cuando la presión intracraneal (PIC) es $>25 \mathrm{~mm} \mathrm{Hg}$ por $>5$ minutos, o PIC $>40 \mathrm{~mm} \mathrm{Hg}$, o presión de perfusión cerebral (PPC) $<40 \mathrm{~mm} \mathrm{Hg}$ por $>2 \mathrm{~h}$. En estos pacientes es recomendado el manitol en dosis de 0,25 a $1,0 \mathrm{~g} / \mathrm{kg}$ intravenoso (IV) en bolo cuando la osmolaridad es menor de $320 \mathrm{mOsm} / \mathrm{L}$ (1). Este es el manejo que recibió nuestra paciente, a pesar de no contar con monitorización invasiva de la PIC.

Inducir una hipernatremia leve de 145 a $150 \mathrm{mmol} / \mathrm{L}$ puede reducir la incidencia y severidad de la $\operatorname{HIC}(26,27)$; la inducción terapéutica de hipotermia $\left(33^{\circ} \mathrm{C}-35^{\circ} \mathrm{C}\right)$ puede ser benéfica al disminuir la producción esplácnica de amonio, restaurar la autorregulación hemodinámica cerebral y disminuir el metabolismo oxidativo dentro del cerebro (28). Debe hiperventilarse $\left(\mathrm{PaCO}_{2}\right.$ de $\left.25-30 \mathrm{~mm} \mathrm{Hg}\right)$ únicamente en presencia de deterioro agudo neurológico, PIC $>20 \mathrm{~mm}$ $\mathrm{Hg}$ con evidencia de flujo cerebral aumentado.

Tabla 3. Paraclínicos iniciales (1).

\begin{tabular}{|c|c|c|}
\hline PT/ INR & Hemograma & $\begin{array}{l}\text { Marcadores } \\
\text { autoinmunes }\end{array}$ \\
\hline Química & Hemoclasificación & ANAS \\
\hline Electrólitos & Niveles de acetaminofén & ASMA \\
\hline Glucemia & Examen toxicológico & Elisa VIH \\
\hline $\begin{array}{l}\text { AST, ALT, F. alkalina } \\
\text { GGT, bilirrubinas, } \\
\text { albúmina }\end{array}$ & $\begin{array}{l}\text { Serologías de hepatitis viral } \\
A, B . C, D, E, V Z V^{*}\end{array}$ & Amilasa y lipasa \\
\hline BUN, creatinina & $\begin{array}{l}\text { Niveles de ceruloplasmina } \\
* *\end{array}$ & $\mathrm{TAC}^{* * *}$ \\
\hline Gases arteriales & BHCG (mujeres) & \\
\hline Ácido láctico & Niveles de amonio & \\
\hline
\end{tabular}

*VZV: herpes-zóster.

** Cuando se considere enfermedad de Wilson.

*** Para evaluar otras causas de hipertensión intracraneal.

AST: alanina aminotransferasa; ALT: aspartato aminotransferasa; GGT: gamma glutamil transpeptidasa; BUN: nitrógeno ureíco; BHCG: gonadotropina coriónica humana-subunidad B; TAC: tomografía axial computarizada; ANAS: anticuerpos antinucleares. ASMA: anticuerpos antimúsculo liso; ELISA: enzyme-linked immunosorbent assay.

\section{Hepatopatía/coagulopatía}

El sangrado espontáneo se presenta en menos del 10\% de los casos, es secundario de la deficiencia hepática y del mayor consumo de factores procoagulantes. En ausencia de sangrado o necesidad de procedimientos (24), la correc- 
ción profiláctica de la coagulopatía no reduce el riesgo de sangrado significativo y puede exacerbar la sobrecarga de volumen, por lo tanto solo se recomienda ante la necesidad de un procedimiento invasivo o la presencia de sangrado, tal como presentó nuestra paciente y para el cual recibió plasma + vitamina K, además del manejo usual para hemorragia digestiva alta.

La N-acetilcisteína (29) ha sido estudiada en la intoxicación hepática por acetaminofén y en causas diferentes a esta, manteniendo su infusión hasta que se resuelve la encefalopatía hepática o hasta que desciendan los niveles de INR. La dosis recomendada es $150 \mathrm{mg} / \mathrm{kg}$ IV en bolo en 15 a 60 minutos, seguido de infusión de mantenimiento de $12,5 \mathrm{mg} / \mathrm{kg} / \mathrm{h}$ por 4 horas, luego $6,25 \mathrm{mg} / \mathrm{kg} / \mathrm{h}$.

\section{Soportes}

Se debe asegurar un estado de euvolemia; si se requiere reanimación, se debe iniciar con solución salina normal (SSN) al 0,9\%, escalonar a vasopresores (noradrenalina) para mantener la presión arterial media $(\mathrm{PAM})>65 \mathrm{~mm}$ $\mathrm{Hg}$ y un objetivo de presión venosa central de 6 para 10 $\mathrm{mm} \mathrm{Hg}(1)$. Se presenta insuficiencia renal aguda en el 50\% de los casos, con indicación de terapia de remplazo renal (tabla 4) en situaciones especiales.

Tabla 4. Indicaciones de hemodiálisis.

\begin{tabular}{l}
\hline Azoemia e hiperpotasemia, más: \\
Oliguria \\
Sobrecarga de volumen \\
Acidosis láctica \\
Amonio $>200$ UMol/L + HIC \\
\hline
\end{tabular}

Respecto al uso profiláctico de antibióticos, no está indicado excepto en caso de progresión de la encefalopatía hepática, hipotensión refractaria, presencia de síndrome de respuesta inflamatoria sistémica (SIRS) o en la preparación para trasplante hepático, tal como lo hizo nuestra paciente (30).

\section{Trasplante (tabla 5)}

Se trata de la única opción de tratamiento para algunas causas específicas de la insuficiencia hepática aguda (24); sin embargo, no está disponible para todos y menos del $10 \%$ de los trasplantes de hígado se realizan en pacientes con insuficiencia hepática aguda. En estos pacientes, las tasas de supervivencia son siempre más bajas que las asociadas con trasplante hepático electivo, y se relacionan con infección durante los primeros 3 meses del posoperatorio, siendo mayor el riesgo entre los receptores de mayor edad y entre los que recibieron injertos de donante sin grupo sanguíneo $\mathrm{ABO}$ idéntico.

Tabla 5. Criterios de selección de pacientes con insuficiencia hepática aguda para trasplante (modificada de: Bernal W, N Engl J Med. 2013;369:2525-34).

\begin{tabular}{lccc}
\hline Factor & $\begin{array}{c}\text { Criterio del } \\
\text { King's College }\end{array}$ & $\begin{array}{c}\text { Criterio } \\
\text { Clichy }\end{array}$ & $\begin{array}{c}\text { Criterio } \\
\text { japonés }\end{array}$ \\
\hline Edad $\dagger$ & Sí & Sí & Sí \\
Causa & Sí & No & No \\
Encefalopatía† & Sí & Sí & Sí \\
Nivel de bilirrubina & Varies & No & Sí \\
Coagulopatía† & Sí & Sí & Sí \\
\hline
\end{tabular}

Varies: indica que el criterio se usa solo en casos no asociados con acetaminofén.

† Este factor es común para todos los modelos.

\section{CONCLUSIONES}

Se describe el caso de una paciente femenina joven, sin historia de enfermedad hepática, tampoco factores de riesgo para esta ni ingesta de tóxicos, pero con un cuadro clínico de insuficiencia hepática fulminante aguda, que ante la rápida evolución clínica de la paciente y la limitación administrativa de un hospital del estado, no se puede asegurar si la insuficiencia hepática estuvo relacionada con la infección por hepatitis $\mathrm{B}$, así como tampoco si se trató de un episodio agudo o una recaída, o si estaba en coinfección con el virus de la hepatitis B, tal como la literatura describe que es más frecuente su presentación; tampoco se descartaron otras etiologías de la hepatitis dado que los estudios requieren previa autorización y remisión, y nunca se obtuvieron los resultados, así como tampoco fue posible la remisión a un centro de trasplante hepático.

Se pone en contexto con este caso, no solo un importante tema, sino el déficit administrativo de nuestras instituciones sociales, olvidadas por el Estado y sin recursos económicos por el desvío de estos, ocasionando un retraso en el acceso oportuno y en la modernización del soporte diagnóstico; asimismo, en la limitación de acceso a centros hospitalarios no solo de mayor complejidad, sino también de orden privado con capacidad de trasplante hepático.

\section{REFERENCIAS}

1. Umaña García P. Manejo de la falla hepática fulminante Experiencia en la Fundación Santa Fe de Bogotá. Acta Med Col. $1990 ; 15(1)$. 
2. Lee WM. Uptodate HEPATOLOGY The Management of Acute Liver Failure AASLD Position Paper. [Online].; 2012 [cited 2013 Nov.].

3. Correa Gaviria S. Reporte de un caso de falla hepática aguda por hepatitis autoinmune en una paciente en tratamiento con interferón pegilado para infección crónica por el virus de la hepatitis C. Rev Col Gastroenterol. 2013;28(1):69-73.

4. Carvajal C. Falla hepática aguda, caso clínico y revisión de la literatura. Acta Col Cuidado Intensivo. 2011;11(4):301-9.

5. Arata $S$. Hepatic failure in pregnancy successfully treated by online hemodiafiltration: Chronic hepatitis B virus infection without viral genome mutation, case report. Hepatol Res. 2013; doi: 10.1111/hepr.12090.

6. ICHAI P,SD. Etiology and prognosis of fulminant hepatitis in adults. liver transplant. 2008;14(10): Suppl 2.

7. Mishra N, Walimbe AM, Arankalle VA. Hepatitis E virus from India exhibits significant amino acid mutations in fulminant hepatic failure patients. Virus Genes. 2013;46:47-53.

8. Devi Salam G. Serum tumor necrosis factor-alpha level in hepatitis E virus-related acute viral hepatitis and fulminant hepatic failure in pregnant women. Hepatol Res. 2013;43:826-835.

9. Jayakumar S. Fulminant viral hepatitis. Crit Care Clin. 2013;29(2013)677-97.

10. Nasser M. Hyperacute drug-induced hepatitis with intravenous amiodarone: Case report and review of the literature. Drug Healthc Patient Saf. 2013;5:191-8.

11. Fink DL BE. Liver transplantation for acute liver failure due to efavirenz hepatotoxicity: The importance of routine monitoring. Int J STD AIDS. 2013;24(10):831-3.

12. Mettananda S. Posterior reversible encephalopathy syndrome in a survivor of valproate-induced acute liver failure: A case report. J Med Case Rep. 2013;7(1):144.

13. Al Mutairi F. Fulminant hepatic failure in association with quetiapine: A case report. J Med Case Reports. 2012;6:418.

14. Liang TJ, Hasegawa $\mathrm{K}$, Rimon $\mathrm{N}$, et al. A hepatitis $B$ virus mutant associated whit an epidemic of fulminant hepatitis. N Engl J Med. 1991;324(24):1705-9.

15. Trepo CG, Robert D, Motin J, et al. Hepatitis B antigen (HBSAg) and/or antibodies (anti-HBS and anti-HBC) in fulminant hepatitis: Pathogenic and prognostic significance. Gut. 1976; 17:10-13.

16. Kitano K, Kobayashi H, Hanamura M, et al. Fulminant hepatitis after allogenic bone marrow transplantation caused by reactivation of hepatitis $B$ virus with gene mutations in the core promotor region. Eur J Haematol. 2006;77:255-8.

17. Khare S, Negi SS, Singh S, et al. Genetic analysis of precore/core and partial pol genes in an unprecedented outbreak of fulminant hepatitis B in India. Epidemiol Infec. 2012;140(10):1823-9.

18. Rivero M, Crespo J, Fábrega E, et al. Apoptosis mediated by the Fas system in the fulminant hepatitis by hepatitis B virus. J Viral Hepatitis. 2002;9(2):107-13.

19. Omata M, Ehata T, Yokosuka T, et al. Hepatitis B virus mutation and fulminant hepatitis. $\mathrm{N}$ Engl J Med. 1991;324(24):1699-1704.

20. Leifeld L, Fielenbach M, Dumolin FL, et al. Inducible nitric oxide synthase (iNOS) and endothelial nitric oxide synthase (eNOS) expression in fulminant hepatic failure. J Hepatol. 2002;37(5):613-9.

21. Silvestre JP. Impact of fulminant hepatic failure in C-reactive protein? J Crit Care. 2010;25(4)657:e7-12.

22. Chu CJ, Hsiao CC, Wang TF, et al. Prostacyclin inhibition by indomethacin aggravates hepatic damage and encephalopathy in rats with thioacetamide-induced fulminant hepatic failure. World J Gastroenterol. 2005;11(2):232-6.

23. Davenport A. Adverse effects on cerebral perfusion of prostacyclin administered directly into patients with fulminant hepatic failure and acute renal failure. Nephron. 1991;59(3):449-54.

24. Bernal W. Acute liver failure: Review article. N Engl J Med. 2013;369:2525-34.

25. Gómez Cabeza de Vaca V. Liver transplantation due to fulminant hepatic failure. Transplant P. 2012;44:2076-7.

26. Murphy N. The effect of hypertonic sodium chloride on intracranial pressure in patients with acute liver failure. Hepatology. 2004;39(2):464-70.

27. Bernal W. Intensive care management of acute liver failure. Semin Liver Dis. 2008;28(2):188-200.

28. Stravitz RT. Therapeutic hypothermia for acute liver failure. Crit Care Med. 2009;37(Suppl 7):S258-64.

29. Hu J, Zhang Q, Ren X, et al. Efficacy and safety of acetylcysteine in «non-acetaminophen» acute liver failure: A meta-analysis of prospective clinical trials. Clin Res Hepatol Gastroenterol. 2015;S2210-7401(15)00031-5.

30. Stravitz RT. Intensive care of patients with acute liver failure: Recommendations of the U.S. Acute Liver Failure Study Group. Crit Care Med. 2007;35(11):2498-508. 